\title{
Recent range-wide demographic expansion in a Taiwan endemic montane bird, Steere's Liocichla (Liocichla steerii)
}

\author{
Bailey D McKay*1, Herman L Mays Jr2, Yi-Wen Peng³3, Kenneth H Kozak4, Cheng-Te Yao5,6, Hsiao-Wei Yuan*3, Pei- \\ Fen Lee ${ }^{7}$ and Fu-Hsiung Hsu ${ }^{8}$
}

\section{Correction}

After the publication of this work [1], we became aware of three minor errors, none of which have anything to do with the content of our paper. As a result, we have now added an acknowledgment for NSC funding to HsiaoWei Yuan. We have also added Hsiao-Wei Yuan as a cocorresponding author. Finally, we have added Pei- Pei-Fen Lee and Fu-Hsiung Hsu to the author list. They provided occurrence data for the Ecological Niche Modeling and felt that they should be co-authors of the study. We apologize for any inconvenience this has caused.

\begin{abstract}
Author Details
'Bell Museum of Natural History, and Department of Ecology, Evolution and Behavior, University of Minnesota, St. Paul, MN 55108, USA, ${ }^{2}$ Geier Collections and Research Building, Cincinnati Museum Center, Cincinnati, OH 45203, USA 35 chool of Forestry and Resource Conservation, National Taiwan University, Taipei, Taiwan, ${ }^{4}$ Bell Museum of Natural History, and Department of Fisheries, Wildlife \& Conservation Biology, University of Minnesota, St. Paul, MN 55108, USA, ${ }^{5}$ Endemic Species Research Institute, Council of Agriculture, Jiji, Taiwan, ${ }^{6}$ Department of Life Sciences, National Cheng Kung University, Tainan, Taiwan, 7 Institute of Ecology and Evolutionary Biology, National Taiwan University, Taipei, Taiwan and ${ }^{8}$ Department of Biological Resources, National Chiayi University, Chiayi, Taiwan
\end{abstract}

Received: 12 May 2010 Accepted: 21 May 2010

Published: 21 May 2010

\section{References}

1. McKay BD, Mays HL Jr, Peng Y-W, Kozak KH, Yao C-T, Yuan H-W: Recent range-wide demographic expansion in a Taiwan endemic montane bird, Steere's Liocichla (Liocichla steerii). BMC Evol Biol 2010, 10:71.

\section{doi: 10.1186/1471-2148-10-153}

Cite this article as: McKay et al., Recent range-wide demographic expansion in a Taiwan endemic montane bird, Steere's Liocichla (Liocichla steerii) BMC Evolutionary Biology 2010, 10:153

*Correspondence: mckay117@umn.edu, hwyuan@ntu.edu.tw

1 Bell Museum of Natural History, and Department of Ecology, Evolution and Behavior, University of Minnesota, St. Paul, MN 55108, USA

3 School of Forestry and Resource Conservation, National Taiwan University, Taipei, Taiwan

Full list of author information is available at the end of the article

Submit your next manuscript to BioMed Central and take full advantage of:

- Convenient online submission

- Thorough peer review

- No space constraints or color figure charges

- Immediate publication on acceptance

- Inclusion in PubMed, CAS, Scopus and Google Scholar

- Research which is freely available for redistribution

Submit your manuscript at www.biomedcentral.com/submit
() Biomed Central 